\title{
Análise do setor de produção e processamento de café em Minas Gerais: uma abordagem matriz insumo-produto
}

\author{
Venússia Eliane dos Santos ${ }^{1}$ \\ Marilia Fernandes Maciel Gomes ${ }^{2}$ \\ Marcelo José Braga ${ }^{2}$ \\ Suely de Fátima Ramos Silveira ${ }^{3}$
}

Resumo: Objetiva-se, neste trabalho, analisar o setor de produção e de processamento do café na estrutura econômica de Minas Gerais, determinando sua importância e seus encadeamentos dentro da estrutura do Estado, mediante a utilização de matriz de insumo-produto. Para tanto, são utilizados os índices de ligação de Rasmussen-Hirschman, a abordagem do campo de influência, o índice puro de ligação (abordagem GHS) e os multiplicadores regionais de produto, renda e emprego. Essas aplicações são complementares na identificação de setores-chave da economia. A matriz utilizada foi regionalizada e refere-se ao ano de 1995. Segundo os índices de ligações de Rasmussen-Hirschman e a análise do campo de influência, o setor de produção de café encontra-se acima da média da economia, apresentando maiores encadeamentos para trás e para frente. Já o setor de processamento de café possui forte poder de encadeamento apenas para trás. Pela análise dos multiplicadores, observou-se que o setor de produção do café apresentou os melhores resultados em termos de geração de produto e renda, enquanto a indústria de café, em termos de produto e emprego.

Palavras-chave: café; Minas Gerais; modelo de insumo-produto; setores-chave.

\footnotetext{
${ }^{1}$ Mestre em Economia Aplicada do Departamento de Economia Rural, Universidade Federal de Viçosa (UFV). E-mail: venussia@gmail.com.

2 Professores doutores do Departamento de Economia Rural, Universidade Federal de Viçosa (UFV). E-mail: mfmgomes@ufv.bremjbraga@ufv.br.

${ }^{3}$ Professora doutora do Departamento de Administração, Universidade Federal de Viçosa (UFV).E-mail: sramos@ufv.br.
} 


\begin{abstract}
The objective of this work is to analyze coffee production and processing in the economic structure of Minas Gerais, to determine its importance and its linkages to the structure of the State economy, by using input-output matrix. Therefore, it is determined linkages indexes of Rasmussen-Hirschman, boarding fields, pure linkage index (GHS) and regional multipliers of product, income and employment. These applications are complementary to the identification of key sectors of the economy. The 1995 input-output matrix was used. Linkages indexes of Rasmussen-Hirschman and the analysis of the influence field pointed out that coffee production presents multiplying indicators above those of the economy, presenting higher backward and forward linkages. The coffee processing sector presents only backward linkage effects. In the multipliers analysis, it was observed that coffee production sector showed better performance in terms of product and income generation, while the coffee processing industry, in terms of product and of job multipliers.
\end{abstract}

Key-words: Coffee, Minas Gerais, input-output model, key sectors.

\title{
Classificação JEL: R10.
}

\section{Introdução}

No Brasil, a contribuição da produção cafeeira para a formação econômica foi uma constante ao longo do tempo, porém, sua participação relativa diminuiu gradativamente, dada a contínua diversificação da pauta de exportações brasileira.

Mesmo assim, o café continua sendo importante gerador de divisas para o país, visto que contribuiu com mais de $2 \%$ do valor total das exportações brasileiras. Em 2002/03, a produção de café no Brasil correspondeu a cerca de 40\% do total mundial, tornando o país o maior produtor e exportador. O Brasil destacou-se também como o segundo maior consumidor de café, com um consumo anual de 13,900 milhões de sacas de $60 \mathrm{~kg}$ (AGRIANUAL, 2005).

Minas Gerais, dentre os estados brasileiros produtores de café, destaca-se como o maior produtor e foi responsável, em $2002 / 03$, por $44,42 \%$ do total produzido internamente. É um dos produtos de maior importância na pauta de exportações mineira e, em 2003, $R$ \$ 2,248 bilhões dos $R \$ 12,501$ bilhões que compuseram o Produto Interno Bruto (PIB) agropecuário do Estado foram advindos do café, caracterizando-o como principal produto agrícola, em termos de receitas (FUNDAÇÃO JOÃO PINHEIRO, 2004).

A importância da cafeicultura mineira pode ser avaliada não apenas pela produção e renda, mas pelo seu papel no mercado de trabalho como geradora de empregos e como fator de fixação de mão-de-obra no meio rural. A cadeia 
produtiva do cafét gera cerca de 4,6 milhões de empregos diretos e indiretos em todo o estado (SAES; NAKAZONE, 2002).

Em 2003, essa cadeia foi responsável por $45,57 \%$ do total exportado pelo agronegócio mineiro, ou seja, por mais de $\mathrm{R} \$ 2$ bilhões dos $\mathrm{R} \$ 5,429$ bilhões da receita de exportação. Associada à cadeia de grãos, foi responsável, em 2003, por 90\% do total do valor exportado pelo agronegócio em Minas Gerais (FAEMG, 2005).

Tratando-se da cadeia produtiva do café, a mais importante do complexo agroindustrial mineiro e que tem buscado incessantemente a maior eficiência e competitividade, ainda não se conhece a sua importância em gerar maior desenvolvimento para o estado, ou seja, a capacidade dessa cadeia, aqui analisada pelo setor de produção e processamento, de incentivar aumento em sua atividade e entre os diferentes setores relacionados a ela. Cada segmento produtivo dessa cadeia influencia e é influenciado pelos padrões de evolução tecnológica dos diferentes segmentos, correlacionados pela difusão das inovações e mudanças nos preços relativos e na demanda derivada.

O setor produtivo e de processamento do café, em razão de absorver matérias-primas de outros setores (adubos, defensivos agrícolas, máquinas e equipamentos) e fornecer insumos para diversas indústrias (de torrefação, de doces e balas, de café solúvel, de produtos medicinais e de alimentos e bebidas em geral), pode apresentar interligações com outros setores da economia. Destarte, os choques ocorridos nesse setor (como oferta, demanda, políticas de retenção de estoques e variações cambiais) podem provocar efeitos multiplicadores sobre a economia nos quais estão inseridos.

Em decorrência dessas e de várias outras características, torna-se interessante a realização de estudos que venham quantificar a importância relativa dos setores de produção e de processamento do café, dentro da estrutura produtiva do estado.

O conhecimento da importância dos setores de produção e de processamento do café dentro da cadeia produtiva tem por finalidade analisar os efeitos que o encadeamento deste pode provocar tanto no próprio setor quanto na economia como um todo, gerando, assim, o crescimento econômico. Além disso, esse conhecimento pode promover o embasamento necessário à tomada de decisões, com vistas em melhorar o seu desempenho. Assim, dado que os setores de produção e de processamento de café apresentam ligações para trás e para frente com outros setores da economia, ou seja, a partir do momento que se compram e vendem produtos de outros setores, influenciam e são influenciados pelas ações dos demais setores, propôs-se, neste trabalho, analisar o setor produtivo e de processamento do café na economia mineira, determinando sua importância e seus encadeamentos dentro da estrutura do estado, mediante a utilização de matriz de insumo-produto no ano de 1995.

\footnotetext{
${ }^{4}$ A cadeia produtiva de café é composta a montante pelo setor que é formado pela indústria fornecedora de insumos, máquinas e equipamentos; unidade de produção agropecuária; e a jusante, pela indústria de beneficiamento e processamento, distribuição, comercialização e colocação do produto final no mercado consumidor.
} 
366 - Análise do setor de produção e processamento de café em Minas Gerais: uma abordagem matriz insumo-produto

O modelo insumo-produto tem sido freqüentemente utilizado, como instrumental, em diversos estudos que objetivam análises intersetoriais na identificação dos setores-chave para o desenvolvimento econômico de determinada região e para análise da importância de setores específicos dentro de determinadas economias. Entre esses estudos, destacam-se os de Santana (1994), Montoya e Guilhoto (2000) e Furtuoso e Guilhoto (2003) que fizeram análises da economia nacional; e de Cavalcanti (1991), Fernandes (1997), Rodrigues et al. (2001), Parré e Guilhoto (2001) e Tosta et al. (2005) que fizeram suas análises em âmbito regional.

Ressalta-se ainda que, em Minas Gerais, não se tem conhecimento de nenhum trabalho que utilizou matrizes de insumo-produto com o intuito de analisar os setores de produção e processamento do café. Dessa forma, estudos que preencham essa lacuna são relevantes para a ampliação do conhecimento acerca desse setor na economia do estado.

\section{Economia cafeeira nas duas últimas décadas}

O setor cafeeiro apresentou mudanças substanciais em competitividade, a partir da década de 90, período em houve quebra de acordos/instituições que defendiam os interesses do setor. Em julho de 1889 houve a suspensão dos Acordos Internacionais do Café (AICs), que mantinham os preços do produto artificialmente elevados, por meio da utilização de cotas de exportação por país produtor (REZENDE; ROSADO; GOMES, 2007).

Em âmbito nacional extingui-se o Instituto Brasileiro do Café (IBC), vigente de 1952 a 1990, responsável pela formulação das políticas externas e internas e pela regulação das exportações, dos estoques e das torrefações. Em 1990, o mercado cafeeiro viu-se livre da intervenção governamental.

No contexto de defesa da produção do café, a indústria de torrefação e moagem possuía papel secundário de absorver o excedente de produção não-exportável. É relevante destacar, no entanto, que esse produto era de qualidade bem inferior à exportada.

Com a suspensão do AIC, foi suscitada uma guerra de preços no mercado internacional de café; em conseqüência, observou-se crescimento da oferta do produto devido à liberação dos estoques por vários países e, por fim, a redução dos preços.

A desregulamentação de mercado, associada à suspensão do AIC, propiciou diminuição da área plantada do produto no País e observou-se queda de 38,8\% na produção brasileira de café, entre 1991 e 1995. Os níveis de produção foram recuperados somente a partir de 1998, em razão da elevação dos preços em 1997. A produção brasileira de café, no período de 1992 a 2006, apresentou taxa de crescimento de $3,4 \%$ ao ano, sempre pautado por altas e baixas em decorrência dos diversos fatores de instabilidades inerentes a sua produção, quais sejam, o caráter bi-anual da atividade, a sensibilidade às variações climáticas e a forte influência de variações de preços e mercados (REZENDE; ROSADO; GOMES, 2007). 
A partir das mudanças ocorridas no mercado do café, houve a necessidade dos produtores de se modernizarem. As propriedades com baixa produtividade e, portanto, pouco competitivas foram perdendo espaço para aquelas que investiam na produção e no negócio.

Passou-se a utilizar técnicas mais sofisticadas, como o adensamento do plantio, nas regiões em que era possível a utilização da mecanização, o que tornou menores as perdas e os custos de produção. Em decorrência disso, a produtividade aumentou 58\% no período de 1992 a 1998 (IBGE, 2007).

As exportações brasileiras apresentaram crescimento de $8,5 \%$ no mesmo período e de 44,4\%, de 1998 a 2005, sendo que nesse último ano o País exportou $28 \%$ do total mundial (IBGE, 2007).

De 1992 a 2005, ocorreu redistribuição geográfica da produção no País, com redução da área plantada em São Paulo $(47,8 \%)$ e ampliação em Minas Gerais $(9,5 \%)$ entre 1992 e 2005. Devido ao clima favorável à produção do café, Minas Gerais tornou-se o maior estado produtor do Brasil (IBGE, 2007).

As principais regiões produtoras de Minas Gerais são Sul de Minas, Zona da Mata e Cerrado (Triângulo Mineiro e Alto Paranaíba). O Cerrado Mineiro vem apresentando o maior crescimento da área plantada, região que incorpora conceitos técnicos modernos de adensamento e mecanização da colheita.

O segmento produtor de café em grãos, segundo Relatório da Comissão Especial da Cafeicultura Mineira (2003), compreende mais de 90.000 propriedades em 697 municípios mineiros, nos quais predomina o sistema de produção tradicional. A estrutura predominante das propriedades nesse segmento é de pequenas e médias, sendo que grande parte dos produtores é associada a uma cooperativa, sindicato ou a alguma associação de classe.

Segundo Abrantes (2006), esses produtores apresentam reduzida capacidade de beneficiamento e de negociação direta da produção com o segmento processador, os quais são realizados por meio de cooperativas, maquinistas e corretores, fato que faz com que Minas Gerais possua "o maior sistema de cooperativista de café do mundo".

Já os grandes produtores de café no estado, dada a sua maior capacidade de processamento da produção, negociam diretamente o produto tanto no mercado interno quanto no externo (ABRANTES, 2006).

O segmento de torrefação e moagem de café constitui-se de 1.200 empresas, que oferecem mais de 2.000 marcas e localizam-se, em sua maioria, nas regiões Sul e Sudeste do Brasil (REZENDE; ROSADO; GOMES, 2007). Minas Gerais, por sua vez, detém mais de $25 \%$ dessas empresas (323) e 38\% desse total de empresas é responsável por mais de $90 \%$ do volume total de café processado. Há alta rotatividade nessa indústria, o que implica grande concorrência. Assim, a permanência nesse ambiente fortemente competitivo é maior para as empresas de grande porte, o que resulta em aumento da concentração dessa indústria que concorre via preços (ABRANTES, 2006). 
Tratando-se de mudanças tecnológicas nesse segmento, observa-se que estas ocorreram principalmente nas embalagens, que, além de possibilitarem uma vida mais longa para o produto, permitem que as empresas de maior eficiência econômica ocupem o lugar das menores e sem escala de produção compatível.

O setor de processamento tem a possibilidade de segmentar o mercado, com vistas em agregar valor em produto por meio da qualidade e atender a nichos específicos de mercado. Ressalta-se que, nesse caso, a procedência da matéria-prima é fator primordial para a qualidade do seu produto.

\section{Metodologia}

\subsection{Referencial teórico}

$\mathrm{O}$ referencial teórico utilizado neste trabalho baseia-se na teoria da análise insumo-produto (LEONTIEF, 1985; CHIANG, 1982; MILLER et al., 1985; HADDAD, 1989) e no modelo de desenvolvimento regional (MIERNYK, 1974; ISARD et. al.,1998).

A preocupação com o desenvolvimento regional e com a interdependência dos setores econômicos não é recente. François Quesnay publicou, na França, um livro intitulado Tableau Économique, em 1758, no qual descreveu o fluxo de produção e dos gastos efetuados entre agricultores, manufatureiros e donos de terra. Posteriormente, Léon Walras foi o pioneiro da formulação matemática voltada ao sistema econômico, o qual considerou, explicitamente, a interdependência dos mercados ao utilizar um sistema de equações simultâneas. Em sua obra Élements $d^{\prime}$ Économie Politique Pure, em 1874, Walras afastou-se dos modelos de equilíbrio parcial para direcionar sua análise para o modelo de equilíbrio geral (LANGONI, 1986).

De acordo com Isard et al. (1998), o campo de estudo da análise regional é interdisciplinar. Embora a abordagem insumo-produto tenha sido inicialmente desenvolvida para uma aplicação em âmbito nacional, desenvolvimentos subseqüentes a esta estenderam para aplicações tanto em âmbito 'sub-nacional' (regional) quanto supranacional (global).

Muitas vezes, os pesquisadores defrontam-se com regiões em desenvolvimento ou economicamente estagnadas ou em declínio. Ao considerar quais seriam as industrias ou serviços que seriam economicamente eficientes para dada região, um conjunto de fatores apresenta-se relevante na escolha da localização. Cada indústria ou conjunto de serviços é único; no entanto, alguns fatores básicos afetam as decisões sobre a localização da indústria ou das atividades de serviços, quais sejam: os custos de acesso aos insumos, matérias-primas, produtos intermediários, serviços, além de capital, trabalho e energia, tanto para dada região quanto para fora dela. Os custos de entrega ao mercado, regional ou nacional, também têm importância na decisão sobre a localização da indústria ou das atividades de serviços. Entretanto, os fatores locacionais têm recebido somente atenção secundária dos analistas e administradores (ISARD, 1998). 
A abordagem comparativa de custos constitui-se de uma série de medidas relacionadas com distribuição regional e localização industrial, como: quociente de localização, coeficientes de localização, curvas de localização, índices de especialização, entre outros (ISARD, 1998).

Segundo Miller (1998), a estrutura básica do modelo insumo-produto pode ser aplicada em diversos tipos de análise, tanto nas voltadas para a economia de uma única região quanto nas destinadas a capturar as formas pelas quais duas ou mais regiões são economicamente conectadas (ou relacionadas).

No caso dos modelos de insumo-produto inter-regionais (para duas ou mais regiões), uma das grandes vantagens está no fato de ser possível modelar e mensurar as interconexões das regiões. Nos modelos com uma única região, as importações e exportação para fora da região analisada são tratadas como exógenas ao modelo.

Tanto os modelos voltados para uma única região quanto os inter-regionais são utilizados quando se deseja analisar as regiões completamente. Os modelos de insumo - produto para uma região "desconectam" a referida região de interesse do resto do País. Nesses estudos, em geral, busca-se quantificar os impactos nos setores de região de interesse, os quais são causados por alterações da demanda final dos produtos produzidos nessa região (Isard, 1960 apud SILVEIRA, 2000).

Conforme enfatizou Santana (1994), a Teoria do Crescimento Desequilibrado, desenvolvida por Hirschman (1958), fundamenta-se na escolha de atividades-chaves capazes de ensejar a implantação e o crescimento de outras atividades interligadas por meio dos efeitos de ligação para frente e para trás.

$\mathrm{O}$ modelo de insumo-produto permite, sistematicamente, quantificar as inter-relações dos vários setores de um sistema econômico (GUILHOTO, 2000). Segundo Montoya (1998), o modelo insumo-produto detecta as conseqüências de uma mudança em um setor da economia sobre outro setor e sobre o conjunto de setores. Dadas as interligações dos diferentes setores que compõem a economia, é possível analisar os que teriam maior poder de encadeamento na economia e, portanto, maior capacidade para responder aos estímulos de dada política (setores-chave).

A partir do modelo do insumo-produto para uma economia regional, é possível analisar o processo de interdependência das relações intersetoriais que reflete a estrutura produtiva de dada economia. Neste trabalho, utilizou-se o modelo regional de insumo-produto e as análises basearam-se nos índices de Rasmussen-Hirschman, do campo de influência, do índice puro de ligações e dos multiplicadores de produto, renda e emprego, apresentados a seguir.

\subsection{Referencial analítico}

Ao determinar os setores-chave da economia, estabelecem-se os setores que devem ser priorizados quanto aos novos investimentos, pois estes poderão aumentar o nível de desenvolvimento regional. O modelo de insumo-produto é 
apropriado para definir esses setores-chave e muitos dos trabalhos que objetivam identificá-los se baseiam nos índices de ligações intersetoriais, como os de Rodriguez (1998), Silveira (2000), Figueiredo (2003), Martins et al. (2003) e Tosta et al.(2005).

A metodologia de Rasmussen (1956) e Hirschman (1958) tornou-se parte de procedimentos utilizados e, geralmente, aceitos para identificação dos setores-chave na economia. Segundo os valores obtidos, podem-se determinar os setores que têm maior poder de encadeamento dentro da economia.

O índice de ligações para trás, de Rasmussen-Hirschman, indica até que ponto um setor demanda insumos da economia em relação aos demais. Valores acima de 1 indicam um setor altamente dependente do restante da economia; esse índice possui poder de dispersão $\left(U_{j}\right)$. Por sua vez, o índice de ligações para frente, de Rasmussen-Hirschman, representa até que ponto um setor tem seus insumos demandados pela economia em relação aos demais. Valores acima de 1 indicam um setor cuja produção é amplamente utilizada pelos demais, e esse índice apresenta sensibilidade de dispersão $\left(U_{i}\right)$. Valores maiores do que um, tanto dos índices de ligações para trás como para frente, indicam setores acima da média e, portanto, considerados setores-chave para o crescimento da economia.

Em sentido mais restrito, de acordo com McGilvray (1977), devem ser considerados setores-chave os que possuírem tanto os índices de ligações para trás quanto os índices de ligações para frente maiores que a unidade. A classificação de setores-chave, segundo os critérios de Rasmussen-Hirschman, é menos rígida e estabelece que os setores que apresentarem índices de ligações para trás ou para frente maiores que 1 constituem setores-chave para o crescimento da economia.

Ao definir $b_{i j}$ como um elemento da matriz inversa de Leontief; $B, B_{j^{*}}$ e $B_{i^{*}}$, respectivamente, como a soma de uma coluna e de uma linha típica de $B ; B^{*}$, a média de todos os elementos de $B$; e $n$, o número de setores da economia, os índices de ligações para trás e para frente poderão ser obtidos, respectivamente, pelas seguintes expressões:

$$
U_{j}=\left[B_{\bullet} / n\right] / B^{*} \quad U_{i}=\left[B_{i} \cdot / n\right] / B^{*}
$$

Por serem normalizados, esses índices são independentes das unidades de medida, o que permite que se façam comparações intersetoriais, inter-regionais e intertemporais. As dispersões dos índices de ligações para trás e para frente são determinadas, respectivamente, por:

$$
V_{j}=\frac{\sqrt{\frac{\sum_{i}^{n}\left(b_{i j}-\frac{B \cdot \bullet_{j}}{n}\right)^{2}}{(n-1)}}}{\frac{B \cdot \bullet_{j}}{n}}
$$

$$
\mathrm{e} \quad V_{i}=\frac{\sqrt{\frac{\sum_{j}^{n}\left(b_{i j}-\frac{B_{i} \bullet}{n}\right)^{2}}{(n-1)}}}{\frac{B_{i \bullet}}{n}}
$$


Os índices de dispersão evidenciam como os efeitos de ligação se espalham pelos demais setores. Baixo valor de dispersão dos índices de ligações para trás significa que o impacto de uma variação da produção em dado setor estimulará os demais de maneira uniforme; alto valor de dispersão, que o estímulo se concentrará em poucos setores. Baixo valor de dispersão dos índices de ligações para frente significa que esse setor será demandado, de maneira uniforme, pelos demais; alto valor, que a demanda por esse setor se concentrará em poucos setores.

Guilhoto et al. (1994) fizeram uma crítica aos índices de Rasmussen-Hirschman, por eles não levarem em consideração os diferentes níveis de produção em cada setor da economia, e destacaram que "apesar de avaliarem a importância de dado setor em termos de seus impactos no sistema como um todo, é difícil visualizar os principais elos de ligações dentro da economia, ou melhor, quais seriam os coeficientes que, alterados, teriam um maior impacto no sistema como um todo".

Com o intuito de corrigir essa deficiência, outros autores desenvolveram diferentes enfoques para o cálculo de índices de ligações intersetoriais em uma economia, os quais podem ser considerados complementares. Dois desses enfoques é o Campo de Influência e os Índices Puros de Ligações, desenvolvidos, respectivamente, por Guilhoto et al. (1994) e Sonis e Hewings (1989).

O campo de influência foi apresentado, de forma mais detalhada, por Sonis e Hewings (1989). Essa abordagem permite verificar como se distribuem as mudanças dos coeficientes diretos no sistema econômico como um todo, possibilitando determinar que relações entre os setores sejam mais importantes no processo produtivo.

O procedimento para o cálculo do campo de influência do setor produtivo e de processamento de café requer a matriz de coeficientes diretos $A=\left|a_{i j}\right|$ e a definição da matriz de variações incrementais nos coeficientes diretos de insumo $E=\left|\varepsilon_{i j}\right|$. As correspondentes matrizes inversas, de Leontief, são dadas por $B=[I-A]^{-1}=\left|b_{i j}\right|$ e por $B(\varepsilon)=[I-A-\varepsilon]^{-1}=\left|b_{i j}(\varepsilon)\right|$.

De acordo com Sonis e Hewings (1989 e 1994), caso a variação seja pequena e só ocorra em um coeficiente direto, tem-se que o campo de influência dessa variação poderá ser aproximado pela expressão:

$$
F\left(\varepsilon_{i j}\right)=\frac{\left[B\left(\varepsilon_{i j}\right)-B\right]}{\varepsilon_{i j}}
$$

em que $F\left(\varepsilon_{i j}\right)$ é uma matriz $(n \times n)$ do campo de influência do coeficiente $a_{i j}$.

Para determinar os coeficientes que possuem o maior campo de influência, é necessário associar-se a cada matriz $F\left(\varepsilon_{i j}\right)$ um valor, que é dado por

$$
S_{i j}=\sum_{k=l}^{n} \sum_{l=1}^{n}\left[f_{k l}\left(\varepsilon_{i j}\right)\right]^{2}
$$

em que $S_{i j}$ é o valor associado à matriz $F\left(\varepsilon_{i j}\right)$. 
A partir dos valores de $S_{i j}$, identificam-se os coeficientes diretos com maior campo de influência, ou seja, é possível indicar as relações setoriais que apresentam maior sensibilidade às mudanças e que possibilitarão maiores impactos na economia como um todo.

O índice puro de ligações (enfoque GHS), desenvolvido por Guilhoto el al. (1996), é um procedimento alternativo para separar os impactos de determinado setor dos demais setores da economia, ou de determinada região do restante da economia ou de determinado país do bloco econômico no qual esteja inserido, considerando as interações dos setores da economia. Os índices puros de ligações levam em consideração o valor da produção em cada setor.

O procedimento consiste em decompor a matriz $A$ de coeficientes técnicos, de Leontief, como segue:

$$
A=\left(\begin{array}{cc}
A_{j j} & A_{j r} \\
A_{r j} & A_{r r}
\end{array}\right)=\left(\begin{array}{cc}
A_{j j} & A_{j r} \\
A_{r j} & 0
\end{array}\right)+\left(\begin{array}{cc}
0 & 0 \\
0 & A_{r r}
\end{array}\right)=A_{j}+A_{r}
$$

em que a matriz $A_{j}$ se refere apenas ao setor $j$ e a suas relações com o resto da economia, e a matriz $A_{r}$, ao restante da economia isolado. Da equação acima pode-se chegar a:

$$
B=(I-A)^{-1}=\left(\begin{array}{ll}
B_{j j} & B_{j r} \\
B_{r j} & B_{r r}
\end{array}\right)=\left(\begin{array}{cc}
\Delta_{j j} & 0 \\
0 & \Delta_{r r}
\end{array}\right)\left(\begin{array}{cc}
\Delta_{j} & 0 \\
0 & \Delta_{r}
\end{array}\right)\left(\begin{array}{cc}
I & A_{j r} \Delta_{r} \\
A_{r j} \Delta_{j} & I
\end{array}\right)
$$

em que

$$
\begin{array}{ll}
\Delta_{j}=\left(I-A_{j j}\right)^{-1} & \Delta_{j j}=\left(I-\Delta_{j} A_{j r} \Delta_{r} A_{r j}\right)^{-1} \\
\Delta_{r}=\left(I-A_{r r}\right)^{-1} & \Delta_{r r}=\left(I-\Delta_{r} A_{r j} \Delta_{j} A_{j r}\right)^{-1}
\end{array}
$$

Tendo por base a equação (6), é possível analisar como se verifica o processo produtivo em uma economia, assim como derivar um conjunto de multiplicadores. Ao considerar as informações contidas naquela equação e usar $X$ $=(I-A)^{-1}$, pode-se ordenar os setores quanto a sua importância no valor da produção gerado, bem como verificar como o processo de produção ocorre na economia. A obtenção destes índices poderá ser dada por:

$$
\left(\begin{array}{l}
X_{j} \\
X_{r}
\end{array}\right)=\left(\begin{array}{cc}
\Delta_{j j} & 0 \\
0 & \Delta_{r r}
\end{array}\right)\left(\begin{array}{cc}
\Delta_{j} & 0 \\
0 & \Delta_{r}
\end{array}\right)\left(\begin{array}{cc}
I & A_{j r} \Delta_{r} \\
A_{r j} \Delta_{j} & I
\end{array}\right)\left(\begin{array}{l}
Y_{j} \\
Y_{r}
\end{array}\right)
$$

que poderá ser descrito por:

$$
\left(\begin{array}{l}
X_{j} \\
X_{r}
\end{array}\right)=\left(\begin{array}{cc}
\Delta_{j j} & 0 \\
0 & \Delta_{r r}
\end{array}\right)\left(\begin{array}{cc}
\Delta_{j} & 0 \\
0 & \Delta_{r}
\end{array}\right)\left(\begin{array}{c}
Y_{j}+A_{j r} \Delta_{r} Y_{r} \\
A_{r j} \Delta_{j} Y_{j}+Y_{r}
\end{array}\right)
$$

em que $A_{j r} \Delta_{r} Y_{r}$ é o impacto direto da demanda final do resto da economia sobre o setor $j$, ou seja, indica o nível de exportação para o setor $j$, necessário para 
satisfazer às necessidades de produção do resto da economia para o nível da demanda final, dado por $Y_{r} ;$ e $A_{r j} \Delta_{j} Y_{j}$, o impacto direto da demanda final do setor $j$ sobre o resto da economia, ou seja, indica os níveis das exportações do resto da economia que são necessários para satisfazer às necessidades de produção do setor $j$ para o nível de demanda final, dado por $Y_{j}$. Dessa forma, ao retornar à expressão (10) obtêm-se as definições de Índice Puro de Ligações para Trás (PBL) e Îndice de Ligações para Frente (PFL), dados por:

$$
P B L=\Delta_{r} A_{r j} \Delta_{j} Y_{j} \quad \text { e } \quad \mathrm{PBL}=\Delta_{j} A_{j r} \Delta_{r} Y_{r}
$$

O PBL representa o impacto puro do valor da produção total do setor $j$ na economia, não se considerando a demanda de insumos que o setor gera internamente $\left(\Delta_{j} Y_{j}\right)$, ou seja, dentro do próprio setor, bem como as demandas da economia como um todo para o setor $j$ e a demanda do setor $j$ para a economia como um todo. Já o PFL indica o impacto puro no setor $j$ da produção total no resto da economia, ou seja, não considera o efeito da demanda de insumos dentro do resto da economia $\left(\Delta_{r} Y_{r}\right)$.

Visto que o PBL e o PFL são expressos em valores correntes, o índice puro do total das ligações (PTL) de cada setor da economia será dado pela soma dos dois primeiros.

Os multiplicadores regionais, por sua vez, referem-se à análise de impactos de elementos exógenos sobre um sistema econômico, tanto no curto quanto no longo prazos. Os três tipos de multiplicadores mais freqüentemente utilizados são os que estimam os efeitos das mudanças exógenas na produção dos setores na economia, na renda ganha pelos consumidores domésticos por causa da nova produção e no emprego (em termos físicos) esperado, a ser gerado pela nova produção.

O modelo para o cálculo dos multiplicadores segue a forma geral $\mathrm{B}=(I-A)^{-1} Y$, em que $B$ é o valor da produção; $(I-A)^{-1}$, matriz inversa de Leontief; e $Y$, demanda final. Seu cálculo permite analisar o impacto de uma variação na demanda final de determinado setor sobre a variável econômica de interesse (MILLER, 1998).

Neste trabalho, utilizaram-se os multiplicadores do tipo I, de forma a captar os efeitos diretos (sobre o próprio setor) e indiretos (sobre os demais setores), em termos de geração de produto, renda ou emprego de um aumento unitário na demanda final do setor. Esses multiplicadores consideram que o consumo das famílias seja exógeno no sistema.

O multiplicador da produção representa a produção adicional gerada em toda a economia, decorrente de alteração na demanda final de determinado setor.

$$
M P_{j}=\sum_{i=1}^{n} b_{i j}
$$

Os multiplicadores da renda, por sua vez, permitem quantificar a renda gerada em toda a economia para cada unidade monetária de renda obtida em determinado setor, em razão do aumento de produção necessário para atender à 
variação de uma unidade da demanda final dele. O multiplicador da renda, para determinado setor $j$, é expresso por:

$$
M R_{j}=\sum_{i=1}^{n}\left(a_{n+1, i} b_{i j}\right) / a_{n+1, j}
$$

em que $j$ representa dado setor da economia; $a_{n+1, i}$, elementos da linha dos coeficientes de remuneração das famílias; e $b_{i j}$, elementos da inversa de Leontief, sem a endogeneização do consumo doméstico das famílias.

Já os multiplicadores de emprego permitem determinar o impacto de mudanças na demanda final do produto, que, por sua vez, leva a variações no nível de emprego. A variação no emprego conduz à variação na renda e, conseqüentemente, na demanda do consumidor. O multiplicador de emprego em um setor $j$ é definido por novos empregos gerados em todos os setores da economia, resultante do aumento de uma unidade monetária de demanda final pelo produto do setor $j$. Algebricamente, o multiplicador de emprego pode ser expresso por:

$$
M E_{j}=\sum_{i=1}^{n}\left(w_{n+1} b_{i j}\right)
$$

em que $w_{n+1}$, é o coeficiente de trabalho físico (número de empregos) por unidade monetária produzida; e $b_{i j}$, elementos da inversa de Leontief, sem a endogeneização do consumo doméstico das famílias. No caso do multiplicador de emprego, ele é dado em unidades físicas e não em unidades monetárias, como em outros multiplicadores.

Neste trabalho são utilizadas informações provenientes da matriz de insumo-produto, calculada por Silveira (2000) para Minas Gerais no ano de 1995. Na matriz utilizada, a fim de atender aos objetivos propostos, o setor Agropecuário foi desagregado no setor Café em coco, e o setor Indústria de produtos alimentares no setor Indústria do café. Na desagregação dos setores foi utilizada a matriz de coeficientes elaborada por Lírio (2001).

\section{Resultados e discussão}

Neste estudo, conforme os valores calculados para os índices de ligação de Rasmussen-Hirschman, no Estado de Minas Gerais (Quadro 1), verificam-se que os setores (9) Indústria do café, (10) Outras indústrias de produtos alimentares e (4) Produtos não-metálicos, siderurgia e metalurgia foram os que apresentaram maiores índices de ligações para trás, ou seja, foram os que se destacaram como importantes compradores para seus fornecedores de bens e serviços. O setor (9), Indústria do café, apontou forte poder de encadeamento para trás e o setor (1), Café em coco, apresentou a oitava posição.

Com relação à dispersão dos índices de ligação para trás, observam-se que os setores (1) Café em coco e (9) Indústria do café apresentaram o $12^{\circ}$ e $16^{\circ}$ menor valor 
de dispersão, respectivamente, o que indica que o impacto de uma variação na produção desses setores deveria estimular maior número de setores da economia.

Dentre os setores mais demandados pelos demais, destacaram-se (4) Produtos não-metálicos, siderurgia e metalurgia, (7) Produtos químicos (altamente demandados pela Agropecuária), (2) Agropecuária e (1) Café em coco.

Os setores (1) Café em coco e (9) Indústria do café ocuparam a 10 a e 1a posições, respectivamente, em termos de dispersões dos índices para frente, $\mathrm{o}$ que indica que o primeiro é demandado por grande número de setores, enquanto o último, além de exercer pouco impacto para frente, é demandado por número pequeno de setores.

Se forem considerados os setores-chave como os que apresentam tanto índices de ligação para trás quanto para frente maior do que 1, têm-se, então, identificados como setores-chave, em Minas Gerais, os seguintes: (1) Café em coco, (4) Produtos não-metálicos, siderurgia e metalurgia e (5) Mecânica, material elétrico e material de transportes. No entanto, segundo uma análise menos restrita, poder-se-ia considerar como setor-chave o setor (9) Indústria do café.

Observou-se em Minas Gerais, no período de 1995 a 2005, crescimento na área e na quantidade produzida de café, o qual passou de 848.060 hectares e 931.983 toneladas para 1.043.308 hectares e 1.002.672 t, respectivamente (AGRIANUAL, 2005). A maior oferta de café, por sua vez, tem refletido em maior uso de máquinas, equipamentos e adubos, ou seja, tem influenciado as ações dos setores que vendem insumos ao setor produtivo de café. Além de fornecer produtos às indústrias de torrefação, proporciona, ainda, produtos para as indústrias de balas e doces, de produtos medicinais e de alimentos e bebidas em geral.

O segmento processador compreende empresas de torrefação e moagem. As empresas filiadas ao Sindicato das Indústrias de Café do Estado de Minas Gerais (Sindicafé-MG) somam 323, das quais 111 localizam-se na região sul do estado. Do volume total do café processado em Minas Gerais, mais de $90 \%$ é realizado por $38 \%$ dessas empresas, que operam numa estrutura de mercado de alta concorrência, com baixo nível tecnológico, e apresentam forte competição via preço. Esse processo levou ao aumento na concentração de pequenas empresas que produziam café de baixa qualidade, em sistemas de produção precários e incipiente nível tecnológico, comercializado a preços predatórios e praticavam a sonegação fiscal (ABRANTES, 2006).

Os resultados encontrados são condizentes com os do trabalho de TOSTA et al. (2005), que analisaram a importância do setor de suínos e de carne suína em Minas Gerais. Os autores supracitados também constataram que os setores com fortes encadeamentos para trás são Fabricação de produtos alimentícios e de bebidas; Máquinas, equipamentos, materiais elétricos e equipamentos de transporte; e com fortes encadeamentos para frente: Agropecuária; Produtos não-metálicos e metalurgia básica; Serviços; Produtos químicos; Fabricação de produtos alimentícios e de bebidas; e Transporte e comunicações. 
376 - Análise do setor de produção e processamento de café em Minas Gerais: uma abordagem matriz insumo-produto

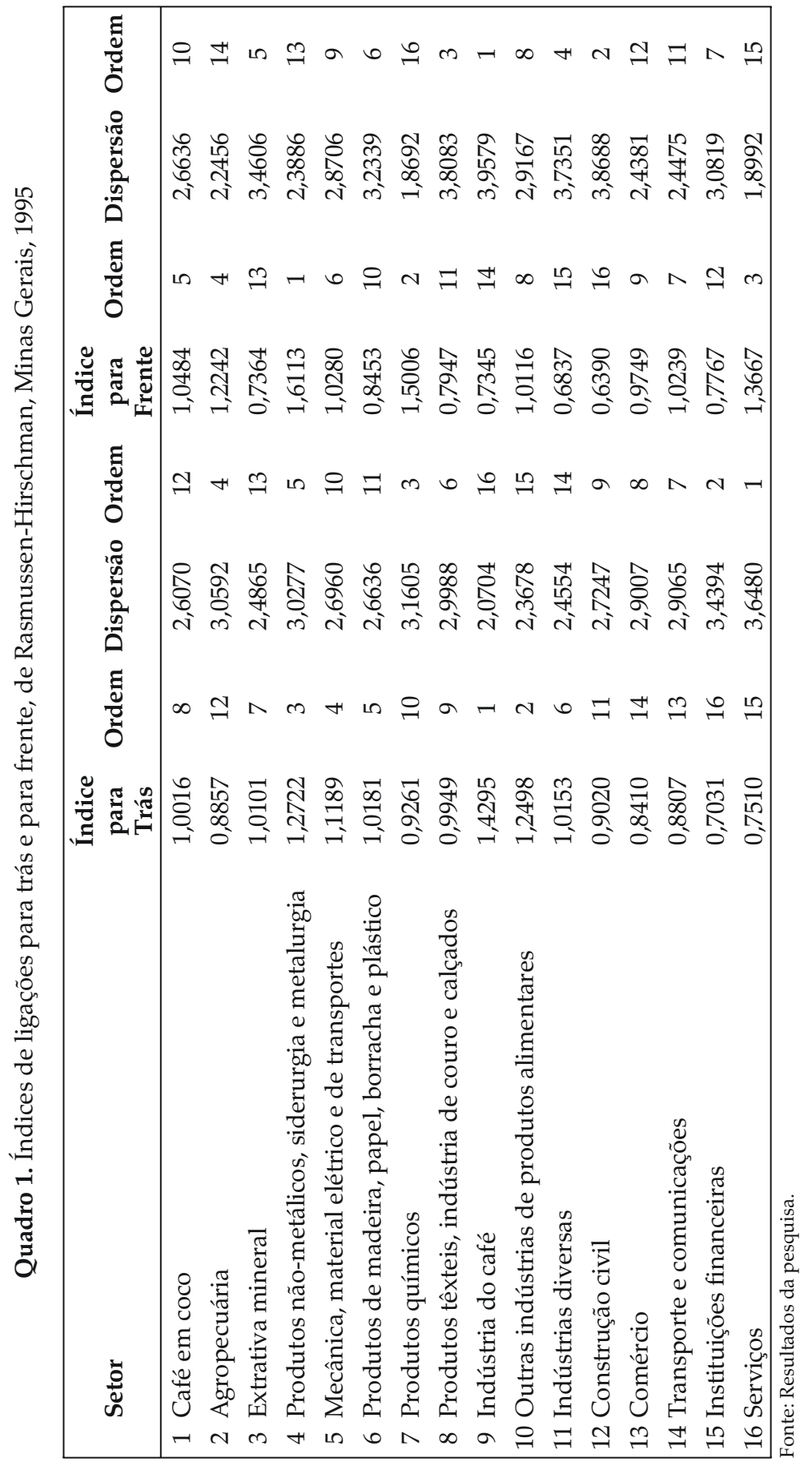

RESR, Piracicaba, SP, vol. 47, no 02, p. 363-388, abr/jun 2009 - Impressa em julho 2009 
Quanto ao setor de produção do café, observa-se, pelos resultados do Quadro 1, que este apresentou forte poder de ligação para trás, ou seja, grande capacidade de influenciar os setores fornecedores de insumos (fungicidas, adubos, defensivos agrícolas), máquinas e equipamentos, e ligação para frente com a indústria de solúvel, torrefação e moagem e cooperativas.

A indústria de máquinas e equipamentos é importante como fornecedora de produtos à produção do café, visto que nesta cultura se utilizam máquinas específicas à produção, entre as quais se destacam as colheitadeiras, os secadores de café, os separadores de grãos, os catadores de pedra e os descascadores de grãos.

No que diz respeito à indústria de torrefação e moagem, verifica-se que esta apresentou fortes encadeamentos para trás, influenciando principalmente o setor de produção, e, em segundo lugar, indiretamente, os mesmos setores que oferecem insumos para a produção de café. Além disso, este setor possui poder de encadeamento sobre setores que fornecem insumos diretamente à indústria, tal como a de embalagens. O setor de processamento de café possui menor capacidade de influenciar os setores que demandam seus produtos, no entanto, destacam-se os varejos nacional e internacional (supermercados, pequeno varejo, mercado institucional, lojas de café e bares e restaurantes).

A análise dos coeficientes do campo de influência permite visualizar os principais elos dos setores dentro da economia. Na Figura 1, apresentam-se os coeficientes do campo de influência no estado de Minas Gerais e, em seus eixos, estão discriminados os setores considerados neste trabalho. Foram escolhidos 128 coeficientes setoriais que apresentavam maior campo de influência.

$\mathrm{O}$ setor que gerou os maiores impactos no sistema econômico de Minas Gerais foi o de (4) Produtos não-metálicos, siderurgia e metalurgia. Variações nos coeficientes diretos deste setor propiciariam maior propagação das relações comerciais intersetoriais para o sistema como um todo, em comparação com os outros setores. Esse setor foi o único que apresentou capacidade de influenciar, em compra e venda, todos os 16 setores, o que comprova sua importância na economia do estado. 
- Análise do setor de produção e processamento de café em Minas Gerais: uma abordagem matriz insumo-produto

Figura 1. Campo de influência, Minas Gerais, 1995.

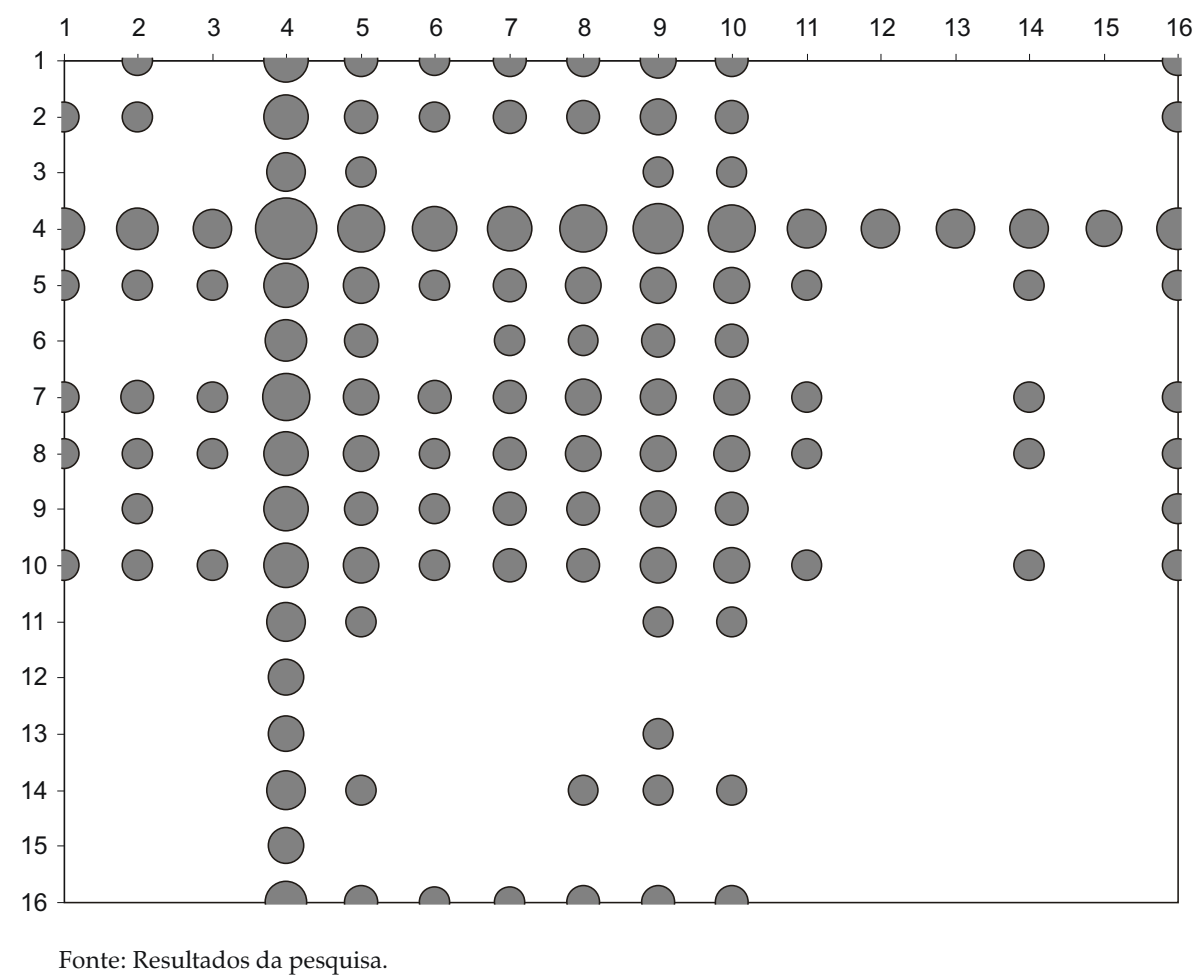

Em geral, os setores identificados como chave, pelo critério de Rasmussen-Hirschman, são também considerados os de maiores coeficientes do campo de influência, o que se justifica pelo fato de que, se o setor tiver fortes ligações tanto de compra quanto de venda, possivelmente exercerá forte influência nas relações de compra e venda da matriz como um todo.

O setor (1), Café em coco, foi importante para os demais setores da economia como ofertante de insumos, pois apresentou nove coeficientes de venda e somente seis para compra. Quanto ao setor (9), Indústria do café, o resultado reafirmou a sua grande capacidade de influenciar para trás, dado que apresentou 14 coeficientes de compra e 9 de venda. Assim, uma variação no coeficiente de produção desse setor influenciaria, expressivamente, os setores que fornecem insumos para sua produção. 
Os resultados encontrados nos Índices Puros de Ligações para trás (PBL), para frente (PFL) e para o total (PTL), na economia do estado de Minas Gerais, são medidos em valores monetários e estão apresentados em mil reais e em valores de 1995 (Quadro 2).

Identificam-se como setores-chave os que obtiveram valores maiores que a média estadual porque suas produções impactaram a produção do resto da economia e foram impactadas por ela, em uma proporção acima da média dentre os demais setores pertencentes à mesma região.

Entre os setores-chave em Minas Gerais, destacaram-se: (4) Produtos não-metálicos, siderurgia e metalurgia; (10) Outras indústrias de produtos alimentares; e (5) Mecânica, material elétrico e material de transportes.

A composição do PTL para o setor (1), Café em coco, indica que 50,68\% de sua estrutura procediam do PFL, resultado esse análogo ao valor do índice de Rasmussen-Hirschman, que apresentou índice de ligação para frente maior que o de ligação para trás.

O resultado encontrado, em termos de ligação para frente e para trás para o setor de produção de café, já era esperado, dado que esse produto tem grande importância dentro da estrutura produtiva de Minas Gerais. A maior parte dos insumos e serviços utilizados na produção de café constitui-se de fungicidas, adubos, novas máquinas e equipamentos para colheita do café, secadores, separadores de impurezas e descascadores de café. Em razão das novas exigências do mercado consumidor, cuja preferência é por produtos de melhor qualidade, tem-se observado significativo aumento no emprego desses últimos equipamentos, como instrumentos utilizados para preservação da qualidade e padronização do produto. 
380 - Análise do setor de produção e processamento de café em Minas Gerais: uma abordagem matriz insumo-produto

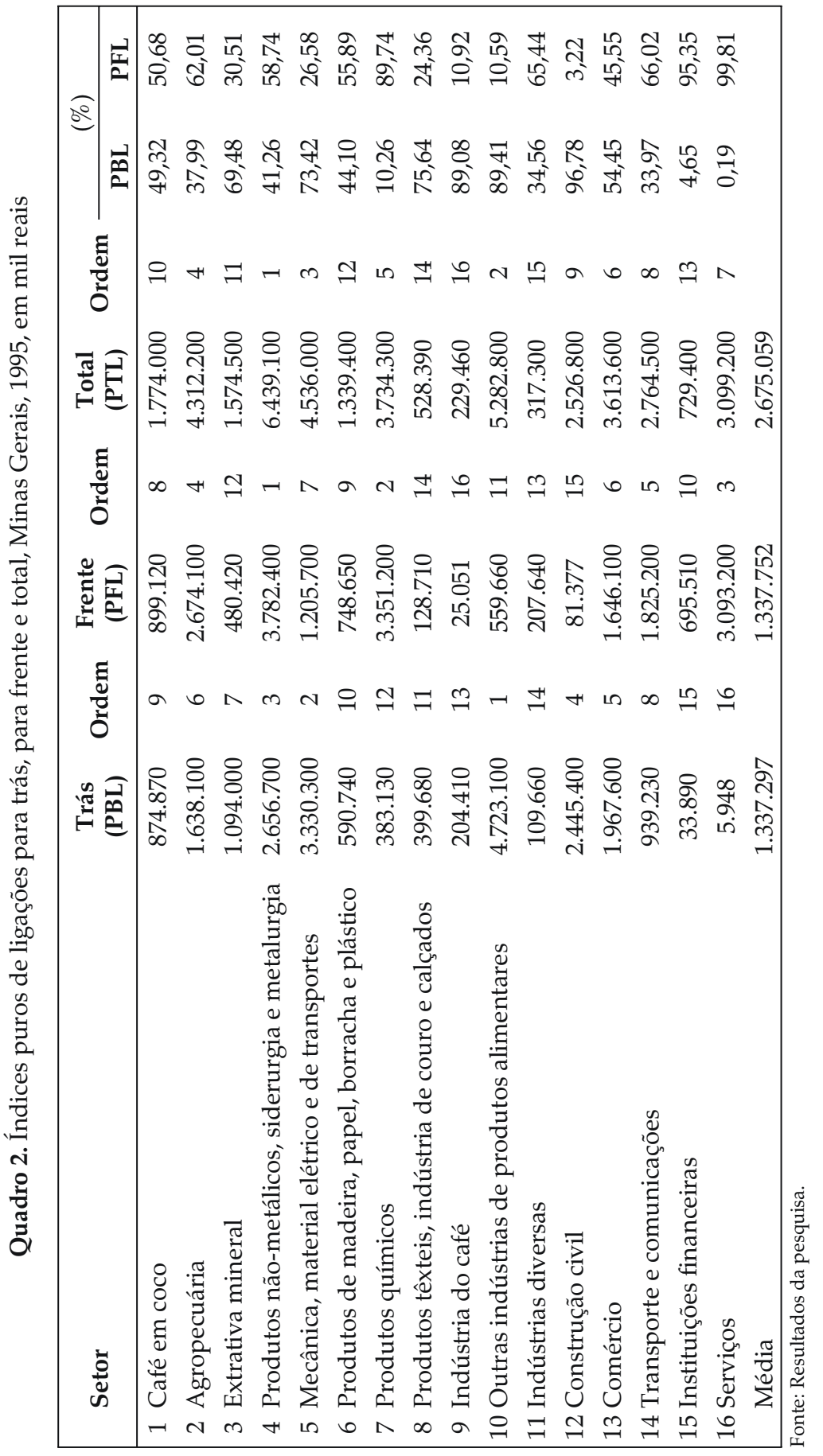

RESR, Piracicaba, SP, vol. 47, no 02, p. 363-388, abr/jun 2009 - Impressa em julho 2009 
Quanto ao setor (9) Indústria do café, este apresentou 89,08\% da composição do PTL em ligações para trás, ou seja, possui maior poder de encadeamento sobre os setores dos quais utiliza insumos, como a produção do café, a indústria de embalagens etc. No entanto, as indústrias de torrefação e moagem de café, em Minas Gerais, absorvem e, ou, processam uma parte muito pequena da produção do estado, dado que a maior parte da produção é adquirida pelas indústrias de café do estado de São Paulo. Em Minas Gerais existem muitas indústrias de torrefação e moagem de café, porém, a grande maioria é de pequeno porte.

No estado de São Paulo torram-se quase 50\% do total produzido no Brasil. Esse estado produz $12,4 \%$ do total de grão verde do País e $48,10 \%$ de café torrado, enquanto Minas Gerais produz 50,8\% de grão verde e apenas 10,5\% de café torrado (ABIC, 2005).

No Quadro 3 apresentam-se os multiplicadores setoriais da produção em Minas Gerais, em 1995.

Observam-se, pelos resultados, que os setores (4) Produtos não-metálicos, siderurgia e metalurgia, (9) Indústria do café e (10) Outras indústrias de produtos alimentares foram os que apresentaram os maiores valores de impacto na produção. O setor (1), Café em coco, apresentou o sétimo maior valor, o que significa que, se a demanda final por produtos do setor cafeeiro aumentar $R \$$ $1.000,00$, ocorrerá uma variação global da produção em todos os setores da economia para atender a essa mudança, da ordem de R $1.657,00$. Em outras palavras, $R \$ 1.657,00$ indicam a quantidade de recursos necessários para produção dos insumos requeridos pelo setor cafeeiro para produzir $\mathrm{R} \$ 1.000,00$ do produto final desse setor, ou a mudança total na capacidade produtiva dos setores requeridos para atender ao estímulo exógeno por produtos do setor cafeeiro.

Quadro 3. Multiplicadores setoriais da produção em Minas Gerais, 1995

\begin{tabular}{|lcc|}
\hline Setores & Multiplicadores & Ordem \\
\hline 1 Café em coco & 1,657 & 7 \\
2 Agropecuária & 1,442 & 13 \\
3 Extrativa mineral & 1,673 & 6 \\
4 Produtos não-metálicos, siderurgia e metalurgia & 2,107 & 2 \\
5 Mecânica, material elétrico e material de transportes & 1,854 & 4 \\
6 Produtos de madeira, papel, borracha e plástico & 1,684 & 5 \\
7 Produtos químicos & 1,534 & 10 \\
8 Produtos têxteis, indústria de couro e calçados & 1,647 & 8 \\
9 Indústria do café & 2,365 & 1 \\
10 Outras indústrias de produtos alimentares & 2,063 & 3 \\
11 Indústrias diversas & 1,644 & 9 \\
12 Construção civil & 1,494 & 11 \\
13 Comércio & 1,393 & 14 \\
14 Transporte e comunicações & 1,459 & 12 \\
15 Instituições financeiras & 1,165 & 16 \\
16 Serviços & 1,244 & 15 \\
\hline
\end{tabular}

Fonte: Resultados da pesquisa. 
O resultado encontrado neste estudo, para o multiplicador da produção no setor (9) Indústria do café, é semelhante ao obtido por DUARTE FILHO et al. (2002), que é de 2,3781, o que indica que este é um dos setores que mais consomem produtos originários do próprio estado, 49,58\% do total dos insumos adquiridos. No referido trabalho regionalizou-se a matriz de insumo-produto de 1996, para Minas Gerais e Resto do Brasil, e calcularam-se os índices de Rasmussen-Hirschman e os multiplicadores da produção para os setores analisados.

Os valores dos multiplicadores da renda estão apresentados no Quadro 4.

Quadro 4. Multiplicadores setoriais da renda em Minas Gerais, em 1995

\begin{tabular}{|lcc|}
\hline Setores & Multiplicadores & Ordem \\
\hline 1 Café em coco & 0,9727 & 3 \\
2 Agropecuária & 1,0077 & 2 \\
3 Extrativa mineral & 0,9123 & 5 \\
4 Produtos não-metálicos, siderurgia e metalurgia & 0,6838 & 12 \\
5 Mecânica, material elétrico e material de transportes & 0,6673 & 13 \\
6 Produtos de madeira, papel, borracha e plástico & 0,7659 & 9 \\
7 Produtos químicos & 0,6368 & 14 \\
8 Produtos têxteis, indústria de couro e calçados & 0,7328 & 10 \\
9 Indústria do café & 0,2938 & 16 \\
10 Outras indústrias de produtos alimentares & 0,4738 & 15 \\
11 Indústrias diversas & 0,7996 & 8 \\
12 Construção civil & 1,0117 & 1 \\
13 Comércio & 0,7197 & 11 \\
14 Transporte e comunicações & 0,8147 & 7 \\
15 Instituições financeiras & 0,9274 & 4 \\
16 Serviços & 0,8224 & 6 \\
\hline
\end{tabular}

Fonte: Resultados da pesquisa.

Os setores que apresentaram maior capacidade de geração de renda, dentre os 16 setores da economia, são: (13) Comércio, (2) Agropecuária e (3) Café em coco. Os setores (1) Café em coco e (9) Indústria do café ficaram na $3^{\underline{a}}$ e $16^{\mathbf{a}}$ posições, respectivamente. Isso indica que, se a demanda final desses produtos aumentar de uma unidade monetária haverá uma variação global da renda em todos os setores da economia para atender a essa mudança, da ordem de 0,9727 e 0,2938 unidades monetárias, respectivamente.

No que diz respeito ao efeito multiplicador de empregos em Minas Gerais, em 1995, de acordo com os valores apresentados no Quadro 5, o setor (11), Indústrias diversas, apresentou as melhores contribuições para o desenvolvimento da economia, com maior participação na geração de 
empregos. Já o setor (1), café em coco, apresentou a $15^{\text {a }}$ posição e o setor (9) Indústria do café a $8^{\text {a }}$ posição na geração de empregos na economia.

A economia cafeeira em Minas Gerais possui forte expressão social, dado o alto emprego de mão-de-obra de baixa qualificação. Considerando-se apenas as atividades relacionadas com a colheita, os gastos com mão-de-obra podem variar de 40 a $90 \%$ do custo total de produção, embora existam variações de acordo com o sistema de produção adotado. Segundo PONCIANO (1995), um hectare de café necessitaria da participação de 114 dias-homem por ano.

Quadro 5. Multiplicadores setoriais do emprego em Minas Gerais, em 1995

\begin{tabular}{|lcc|}
\hline Setores & Multiplicadores & Ordem \\
\hline 1 Café em coco & 0,007 & 15 \\
2 Agropecuária & 0,006 & 16 \\
3 Extrativa mineral & 0,018 & 11 \\
4 Produtos não-metálicos, siderurgia e metalurgia & 0,016 & 12 \\
5 Mecânica, material elétrico e material de transportes & 0,013 & 13 \\
6 Produtos de madeira, papel, borracha e plástico & 0,022 & 10 \\
7 Produtos químicos & 0,006 & 15 \\
8 Produtos têxteis, indústria de couro e calçados & 0,129 & 3 \\
9 Indústria do café & 0,033 & 8 \\
10 Outras indústrias de produtos alimentares & 0,024 & 9 \\
11 Indústrias diversas & 0,457 & 1 \\
12 Construção civil & 0,037 & 7 \\
13 Comércio & 0,128 & 4 \\
14 Transporte e comunicações & 0,047 & 5 \\
15 Instituições financeiras & 0,038 & 6 \\
16 Serviços & 0,444 & 2 \\
\hline
\end{tabular}

Fonte: Resultados da pesquisa.

No entanto, de acordo com Najberg et al. (2004), com a abertura da economia brasileira e com a globalização tornou-se necessário que as empresas fossem cada vez mais eficientes, o que, muitas vezes, significa a utilização de máquinas em detrimento do uso de mão-de-obra e tendência de redução do emprego nesse setor. Com relação ao trabalho mencionado, os setores com maior potencial de geração de empregos no País são os de serviços (saúde, educação e lazer), agropecuário, madeira e mobiliário, calçados, vestuário e indústria do café. 


\section{Conclusões}

De acordo com os resultados encontrados pela análise dos índices de Rasumssen-Hirschman e do campo de influência, o setor (1), Café em coco, possui grande importância para a economia mineira quanto ao encadeamento, pois possui forte relação com os fornecedores de insumos para sua produção e com os setores demandantes de sua produção. Quanto aos multiplicadores, confirmou-se a expectativa da relevância do setor de produção do café na formação dos indicadores socioeconômicos mineiros, principalmente no que se refere à geração de produção e renda.

O setor (9), Indústria de café, mostrou grande poder de encadeamento para trás, ou seja, influenciou fortemente os setores que lhe forneciam insumos, entre eles, o próprio setor de produção do café. Esta conclusão é corroborada pelos coeficientes do campo de influência e dos índices de ligações de Rasmussen-Hirschman. A análise dos multiplicadores, por sua vez, indicou ser esse setor importante na geração de produto e empregos.

De maneira geral, os resultados produzidos neste trabalho indicam que os setores produtivos do café em coco e da indústria do café contribuem, significativamente, para o crescimento da economia mineira. Os incentivos direcionados aos setores mencionados, além de aumentarem os níveis de produto, renda e emprego nos próprios setores, provocam externalidades positivas nos demais setores da economia estadual, o que corrobora a hipótese preconizada na pesquisa.

\section{Referências Bibliográficas}

ABIC - ASSOCIAÇÃO BRASILEIRA DA INDÚSTRIA DE CAFÉ. Dados Gerais. Disponível em: < http://www.abic.com.br > . Acesso em 2005.

ABRANTES, L. A. Tributos indiretos nos segmentos de produção, torrefação e moagem do café em Minas Gerais. Lavras : UFLA, 2006. 183 p. (Tese Doutorado).

AGRIANUAL - Anuário Estatístico da Agricultura Brasileira. São Paulo: FNP Consultoria \& Agroinformativos, 2005. 520 p.

CAVALCANTI, J. E. A. Relações estruturais na economia brasileira: o caso do Nordeste. Revista Econômica do Nordeste, Fortalezi, v. 22, n 1-4, jan/dez. 1991.

CHIANG, A. C. Matemática Para Economistas. $1{ }^{a}$ Ed. São Paulo: Editora Makron Books/McGraw-Hill, Inc, 1982. 684 p.

COMISSÃO ESPECIAL DA CAFEICULTURA MINEIRA. Relatório Final. Assembléia Legislativa. Belo Horizonte. Dezembro, 2003. 74p. 
DUARTE FILHO, F. C., CHIARI, J. R. P. Características estruturais da economia mineira: Uma análise iner-regional de insumo-produto. In: Cadernos BDMG (Banco de Desenvolvimento de Minas Gerais - BDMG). Belo Horizonte, MG, n 4, Jan de 2002.

FEDERAÇÃO DA AGRICULTURA DO ESTADO DE MINAS GERAIS - FAEMG. Balança comercial do agronegócio mineiro. Disponível em $<$ http//www.faemg.org.br $>$. Acesso em março de 2005.

FERNANDES, C. L. L., A inserção de Minas Gerais na economia nacional: uma análise insumo-produto inter-regional. Nova Economia, Belo Horizonte, número especial, 1997, p. 85-178.

FIGUEIREDO, M. G. Agricultura e estrutura produtiva do estado do Mato Grosso: uma análise insumo-produto. 2003. 206 f. Dissertação (Mestrado em Economia Aplicada) - Escola Superior de Agricultura "Luiz de Queiroz", Universidade de São Paulo, Piracicaba, 2003.

FUNDAÇÃO INSTITUTO BRASILEIRO DE GEOGRAFIA E ESTATÍSTICA. Dados Emprego. Disponível em: < http://www.sidra.ibge.gov.br>. Acesso em: 2005.

FUNDAÇÃO INSTITUTO BRASILEIRO DE GEOGRAFIA E ESTATÍSTICA. Dados

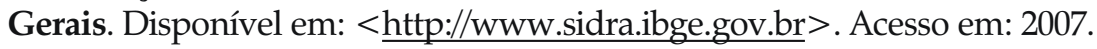

FUNDAÇÃO JOÃO PINHEIRO, Informativo CEI - Produto interno bruto de Minas Gerais - 2003. Belo Horizonte: jun/2004. 12 p.

FURTUOSO, M. C. O., GUILHOTO, J. J. M. Estimativa e mensuração do produto interno bruto do agronegócio da economia brasileira, 1994 a 2000. Revista de Economia e Sociologia Rural. V. 41, n. 4, p. 803-827, 2003.

GUILHOTO, J. J. M., SONIS, M., HEWINGS, G. I. D., MARTINS, E. B. Índices de ligações e setores-chave na economia brasileira: 1959/90. Pesquisa e Planejamento Econômico, v. 24, n. 2, p. 287-314, agosto de 1994.

GUILHOTO, J. J. M, SONIS, M., HEWEINGS, G. J. D. Linkages and multipliers in a multiregional framework: integration of alternative approaches. Illinois: University of Illinois, Regional Economics Applications Laboratory, 1996. 20 p.

GUILHOTO, J. J. M. Leontief e insumo-produto: antecedentes, princípios e evolução. Piracicaba: ESALQ-USP, 2000. 43p.

HADDAD, P. R. Economia regional: teoria e métodos de análise. Fortaleza: BND Etene, 1989.

HIRSCHMAN, A. The strategy of economic development. New Haven: Yale Universitu Press, 1958. 
386 - Análise do setor de produção e processamento de café em Minas Gerais: uma abordagem matriz insumo-produto

ISARD, W. Location analysis for industry and service trades: comparative cost and other approaches. In: ISARD, W. et al. Methods of Interregional and regional analysis. Ashgate Publishing Company USA, 1998, p. 6-39.

ISARD, W. et al. Methods of interregional and regional analysis. Ashgate Publishing Company USA, 1998.

LANGONI, C. G. Apresentação. In: Leontief, W. A Economia do Insumo-produto, 2ª ed., São Paulo: Nova Cultural, 1986, p. VII - XVII.

LEONTIEF, W. Input-Output Economics. New York: Oxford University Press, 1985. p. 19-39.

LÍRIO, V. S. Do Mercusul à Alça: impactos sobre o complexo agroindustrial brasileiro. 2001. 207 f. Tese (Doutorado em Economia Rural) - Universidade Federal de Viçosa, Viçosa, 2001.

McGILVRAY, J. Linkages, key and development strategy. In: LEONTIEF, W. (Ed). Structure, system and economic policy. Cambridge: University Press, 1977. p. 49-56.

MIERNYK, W. H. Elementos de análise do insumo-produto. São Paulo: Editora Atlas. 1974, 158 p.

MILLER, R. E, BLAIR, P. D. Input-output analysis: foundations and extensions. Prentice Hall, inc. 1985.

MILLER, R. E. Regional of Interregional and Regional Analysis. In: ISARD, W. et al. Methods of Interregional and regional analysis. Ashgate Publishing Company USA, 1998, p. 41-70.

MONTOYA, M. A. A matriz de insumo-produto internacional do MERCOSUL em 1990: a desigualdade regional e o impacto intersetorial do comércio inter-regional. 1998. 217f. Tese (Doutorado em Economia) - Escola Superior de Agricultura "Luiz de Queiroz", Universidade de São Paulo, Piracicaba.

MONTOYA, M. A., GUILHOTO, J. J. M. O agronegócio brasileiro entre 1959 e 1995: dimensão econômica, mudança estrutural e tendências. In: O agronegócio brasileiro no final do século XXI: estrutura produtiva, arquitetura organizacional e tendências. Passo Fundo (RS), UPF editora, 2000, cap. 1, p. 3-32, v. 1.

NAJBERG, S.; PEREIRA, R. O. Novas estimativas do Modelo de geração de empregos do BNDES. Rio de Janeiro: BNDES, Sinopse Econômica, n 133, $\operatorname{mar} / 2004,8 \mathrm{p}$.

PARRÉ, J. L., GUILHOTO, J. J. M. A desconcentração regional do agronegócio brasileiro. Revista Brasileira de Economia. Rio de Janeiro, v. 55, n 2, p 223-251, abr/jun de 2001. 
PONCIANO, N. J. Segmento exportador da cadeia agroindustrial do café brasileiro. 1995. 128 f. (Dissertação de mestrado) - Departamento de Economia Rural, Universidade Federal de Viçosa, Viçosa, 1995.

RASMUSSEN, P. N. Studies in inter-sectorial relations. Amsterdam: North-Holland, 1956.

REZENDE, A. M., ROSADO, P. L., GOMES, M. F..M. Café para todos: a informação na construção de um comércio de café mais justo. Consórcio Brasileiro de Pesquisa e Desenvolvimento do Café. EMBRAPA. 2007. 142p.

RODRIGUES, R. L., PARRÉ, J. L., MORETTO, A. C. Dimensionamento e evolução do agronegócio no Paraná. In: CONGRESSO BRASILEIRO DE ECONOMIA E SOCIOLOGIA RURAL, XXXIX, 2001, Recife. Anais...Recife, SOBER, 2001. CD ROM.

RODRIGUEZ, M. A. M. A matriz de insumo-produto internacional do MERCOSUL em 1990: a desigualdade regional e o impacto intersetorial do comércio inter-regional. 1998. 217 f. Tese (Doutorado em Economia) - Escola Superior de Agricultura "Luiz de Queiroz", Universidade de São Paulo, Piracicaba, 1998.

SAES, M. S. M., NAKAZONE, D. Estudo da competitividade de cadeias integradas no Brasil: impactos das zonas de livre comércio - Cadeia: Café, Campinas: dezembro de 2002. 142 p.

SANTANA, A. C. A dinâmica do complexo agroindustrial e o crescimento econômico no Brasil. 1994. 302 f. Tese (Doutorado em Economia Rural) Universidade Federal de Viçosa, Viçosa, 1994.

SECEX - Secretaria de Comércio Exterior. Balança Comercial - Unidades da Federação. Disponível em: 〈http://www.desenvolvimento.gov.br/sitio/^. Acesso em 2007.

SILVEIRA, S. F. R. Inter-relações econômicas dos estados na bacia do rio São Francisco: uma análise de inumo-produto., 2000. 245 f. Tese (Doutorado em Economia Aplicada) - Escola Superior de Agricultura "Luiz de Queiroz", Universidade de São Paulo, Piracicaba, 2000.

SONIS, M., HEWINGS, G. J. D. Error and sensitivity input-output analysis: a new approach. In MILLER, R. E., POLENSKE, K. R., ROSE, A. Z. (Ed). Frontiers of Input-Output Analysis. New York: Oxford University Press, 1989. 
388 - Análise do setor de produção e processamento de café em Minas Gerais: uma abordagem matriz insumo-produto

SONIS, M., HEWINGS, G. J. D. Fields of influence in input-output systems. Urbana, University of Illinois, Regional Economics Applications Laboratory, 1994.

TOSTA, M. C. R., GOMES, M. F. M., LIRIO, V. S., SILVEIRA, S. F. R. Importância e encadeamento dos setores de produção e abate e processamento da cadeia suinícola em Minas Gerais. Revista de Economia e Sociologia Rural - SOBER. Brasília, v.43, n. 2, abr/jun de 2005. 